1110 ESTIMATION OF IMPACTS OF PNEUMOCONIOSIS: A 15YEAR NATIONWIDE COHORT STUDY IN TAIWAN

1,2,3 Lukas Jyuhn-Hsiarn Lee ${ }^{*},{ }^{4}$ Yawen Cheng, ${ }^{1} Y u-Y i n$ Chang, ${ }^{5,6}$ Jung-Der Wang. ${ }^{1}$ National Institute of Environmental Health Sciences, National Health Research Institutes, Zhuna, Taiwan; ${ }^{2}$ Institute of Occupational Medicine and Industrial Hygiene, National Taiwan University, Taipei, Taiwan; ${ }^{3}$ Department of Environmental and Occupational Medicine, National Taiwan University Hospital, Taipei, Taiwan; ${ }^{4}$ Institute of Health Policy and Management, National Taiwan University, Taipei, Taiwan; ${ }^{5}$ Department of Public Health, College of Medicine, National Cheng Kung University, Tainan, Taiwan; ${ }^{6}$ Department of Occupational and Environmental Medicine, National Cheng Kung University Hospital, Tainan, Taiwan

\subsection{6/oemed-2018-ICOHabstracts.1091}

Introduction Few studies estimated life years lost and lifetime costs resulted from pneumoconiosis. We aimed to assess the expected life years lost (EYLL) and lifetime healthcare expenditures (LTHE) in patients with pneumoconiosis in Taiwan.

Methods A cohort of patients with pneumoconiosis was established by recruiting new cases aged 25 or older from the National Health Insurance (NHI) reimbursement dataset. The case was defined by at least 3 times of outpatient clinic visits or hospitalisation with disease diagnosis using ICD-9-CM codes 500-505 for the period 1998-2012. The cohort was linked with National Mortality Registry to verify survival status. Using a semi-parametric method, we extrapolated lifetime survival function under the assumption of constant excess hazard. For each patient, we simulated gender-, and age-matched referents based on the life table from national statistics to estimate the EYLL for the cohort. The LTHE were estimated by multiplying the survival probability with mean monthly costs paid by the NHI for diagnosis and treatment and summing this for the expected lifetime.

Results A total of 34749 pneumoconiosis patients during the 15 years period, approximating an average of 2482 cases per year, were identified through NHI scheme in Taiwan. We estimated that the EYLL due to overall pneumoconiosis was 2.45 \pm 0.1 years. The average EYLL resulted from asbestosis, silicosis, and coal workers' pneumoconiosis were $3.32 \pm 0.7$ years, $4.29 \pm 0.41$ years, $2.66 \pm 0.2$ years, respectively. The LTHE for pneumoconiosis was NT $\$ 708,114 \pm 10,859$, higher in females than males $(749,200$ vs 694,518). Asbestosis ranked top among different types of pneumoconiosis.

Conclusion The accumulated disease burden in terms of total EYLL for pneumoconiosis was estimated more than 90000 life years. The disease burden for pneumoconiosis is substantial. We recommend appropriate measures should be taken for prevention of pneumoconiosis.

\section{NIGHT SHIFT WORK: WHAT ARE THE HEALTH REPERCUSSIONS OF NURSES IN MOROCCO?}

M Lghabi*, W Allouche, B Benali, A El Kholti. Casablanca, Faculty of Medicine and Pharmacy, Hassan II University, Morocco

\subsection{6/oemed-2018-ICOHabstracts.1092}

Introduction night work (NW) is neither natural, in terms of chronobiological rhythms, nor without risks to the health and quality of living conditions. He is suspected of having a role in various health problems (cardiovascular diseases, diabetes, psychosocial risks). WHO sees it as a probable carcinogen (breast cancer +++ ).
Methods This is a descriptive quantitative study of a sample of 69 nurses from a regional hospital. The aim is to assess the repercussions of night work on the physical, mental, family and social levels of nurses.

Result more than $61 \%$ of nurses are over 40 , with female predominance (56\%). 52\% have more than 10 years of professional experience. Gastro-intestinal complaints were revealed in the majority of nurses (bloating 53\%, epigastralgia 40\%). $97 \%$ say that NW is a mental load (stress 82\%). $77 \%$ were victims of violence. 54\% have difficulty falling asleep. $77 \%$ have never received medical surveillance.

Discussion several studies reports that NW is more common in women, and this is also noted in our study (56\%). They show the negative impact of NW on health, namely digestive and sleep disorders which agrees with our study (bloating 53\%, difficulty falling asleep 54\%). Moreover, with regard to medical surveillance, only $23 \%$ of the nurses in our study benefited from it, whereas the NW is considered as a real public health issue in the developed countries.

Conclusion the NW is recognised as a factor of painfulness. In addition to medical follow-up of the employees concerned, appropriate preventive measures must be introduced, while improving the conditions and organisation of work, providing specific information and training on the risks involved, acting on the lifestyle and sleeping hygiene, improve artificial light.

\section{CHALLENGES IN EARLY DETECTION OF NEW AND EMERGING OCCUPATIONAL RISKS -THE CASE OF SPAIN}

${ }^{1,2} \mathrm{R}$ Marinas-Sanz, ${ }^{1,3} \mathrm{Y}$ Casalod, ${ }^{3} \mathrm{M}$ Larrosa, ${ }^{3} \mathrm{~S}$ Laguna, ${ }^{1,3} \mathrm{M}$ Bolea, ${ }^{1,3} \mathrm{~B}$ Martínez-Jarreta.
${ }^{1}$ Consolidated Group of Scientific Research GIIS-063 of Aragon Institute of Health,
Zaragoza, Spain; ${ }^{2}$ Department of Internal Medicine, 'Lozano Blesa' Clinical University
Hospital, Zaragoza, Spain; ${ }^{3}$ Department of Occupational Medicine, Faculty of Medicine,
University of Zaragoza, Zaragoza, Spain

\subsection{6/oemed-2018-ICOHabstracts.1093}

Introduction Different systems and methodological approaches have been developed internationally for the early identification of new and emerging occupational risks as well as for the monitoring of work related diseases. In Spain, a variety of them have been implemented at national and regional levels. This study is not only aimed to provide an up to date comprehensive perspective of all of them, but also to identify current challenges and barriers in their practical implementation and potential solutions.

Methods Literature review and in-depth description of existing systems at local and National levels in Spain through interviews of National experts $(n=17)$ and qualitative analysis. Adding to that, professionals involved in those systems were invited to complete a questionnaire (participants: General Practitioners, Medical Doctors from the Spanish National Health System, Occupational Physicians, experts and Occupational Health workers from Mutual Societies and private companies; $\mathrm{n}=306$ ).

Results Spanish existing systems at National and local levels are described and compared. The exception to the regional fragmentation is the nationwide system of epidemiological health surveillance of workers exposed to asbestos. Furthermore, one of the main limitations to the early identification of new and emerging occupational risks is the lack of dissemination of the existence of these systems among professionals responsible for the Occupational Health within private companies. In fact, only $36 \%$ of these professionals have been 
informed on them and $45,1 \%$ stated to be aware of Occupational Diseases notification systems. Another challenge to overcome is the poor communication between private companies and the public health system.

Discussion This study adds the Spanish perspective to an issue that is being deeply measured in Europe, and possibly pointing towards the need of promoting integrative approaches that involve Health and Work Administration and private firms, etc., in Early Detection of New and Emerging Occupational Risks.

\section{ACCESSING OCCUPATIONAL HEALTH INFORMATION - THE SPANISH WORKER'S PERSPECTIVE}

${ }^{1} S$ Castro-Fernández, ${ }^{2,3}$ E Abecia, ${ }^{4}$ JS Stocks, ${ }^{2,3}$ B Martínez-Jarreta*. ${ }^{1}$ Occupational Health Service. Monforte de Lemos Hospital, Lugo, Spain; ${ }^{2}$ Consolidated Group of Scientific Research GIIS-063 of Aragon Institute of Health, Zaragoza, Spain; ${ }^{3}$ School of Occupational Medicine, University of Zaragoza, Zaragoza, Spain; ${ }^{4}$ Institute of Population Health, University of Manchester, Manchester, UK

\subsection{6/oemed-2018-ICOHabstracts.1094}

Introduction If the occupational health $(\mathrm{OH})$ information provided to workers is to be effective it must be responsive to the needs of the worker. To date little is known about how often workers access such information or their preferences on how to obtain such information, and their level of trust in the information accessed. Our aim is to identify these needs and preferences in the Spanish working population, and to compare them with the results observed in other countries.

Methods 2268 workers attending for routine screening during a 3 month period in 2014 at the $\mathrm{OH}$ services in NHS hospitals and mutual societies in Galicia (Spain), were invited to complete a questionnaire. All workers had been provided with the legally-required $\mathrm{OH}$ information. The questionnaire was developed using French workers ${ }^{1}$ and subsequently modified and validated in the Spanish context.

Results 1559 (69\%) workers completed the questionnaire. Of these $1247(80 \%)$ stated a need for more information on occupational hazards but only 686 (44\% actually sought such information. For those seeking information, the internet was most frequently used $(85 \%)$ despite low confidence in the quality of the information (21\%). For personal advice workers preferred the family doctor (72\%) and less frequently the occupational physician $(19 \%)$ and information from the family doctor was considered more reliable (56\% vs $43 \%$ ). These observations are similar to those made in French and Dutch workers.

Discussion Spanish workers expressed a substantial need for $\mathrm{OH}$ information yet many did not obtain this information. They often accessed resources they considered as less reliable such as the internet or had consulted with professionals lacking specialist expertise in $\mathrm{OH}$. This study adds the Spanish perspective to that already measured in France and the NL and shows similar findings, possibly pointing towards the need for a European-wide strategy to tackle this problem.

\section{OBSTRUCTIVE SLEEP APNEA SCREENING FOR COMMERCIAL MOTOR VEHICLE DRIVERS}

Shari Miller*. Rochester Regional Health, Rochester, USA

10.1136/oemed-2018-ICOHabstracts. 1095
Introduction In the United States in 2015, there were 415000 accidents involving large trucks resulting in 3589 fatalities. The majority of fatal crashes occurred between 12 $\mathrm{pm}$ and $3 \mathrm{pm}$ and fatigue was the number one cause of fatal crashes that involved driver impairment-related factors. Obstructive Sleep Apnea (OSA) affects 3 to 7 percent of the male population and sleepiness in drivers is dangerous leading to decreased alertness, judgment and slower reaction times resulting in an increase of motor vehicle accidents (MVA). Screening for OSA in commercial motor vehicle drivers was inconsistent among the seven providers certified to provide Department of Transportation (DOT) physicals in four different offices of Rochester Regional Health.

Methods Implementation of the Joint Task Force (JTF) Guidelines developed by the American College of Occupational and Environmental Medicine, the American College of Chest Physicians and the National Sleep Foundation followed education sessions for certified examiners and resources for OSA referrals if necessary. The JTF guidelines consist of measureable biometric screenings including body mass index and measurement of neck circumference; use of the Epworth Sleepiness Scale; subject evaluation of sleep symptoms; and screening for hypertension to provide an evaluation measure to screen for OSA and three criteria for driver certification based on the outcome.

Results Over an 8 week period, 102 drivers were screened using the JTF guidelines resulting in 100\% compliance and appropriate referrals for OSA testing or documentation of continued positive airway pressure (CPAP) compliance in drivers with a history of OSA.

Discussion Using a consistent screening tool to evaluate for OSA in drivers improves the practice of occupational medicine while ensuring personal and public safety by reducing the risk of motor vehicle accidents.

\section{SUFFERING AT WORK OF HOSPITAL DOCTORS: REVIEW OF THE LITERATURE OF ANXIETY AND MOOD DISORDERS}

${ }^{1,2}$ Pougnet Richard, ${ }^{3}$ Pougnet Laurence, ${ }^{4}$ Garlantézec Ronan, ${ }^{1,2}$ Dewitte Jean-Dominique,
1,2 Loddé Brice. ${ }^{1}$ Centre de Pathologies Professionnelles, CHRU de Brest, Université de
Bretagne Occidentale, Brest; ${ }^{2}$ EA 4686, Éthique, Professionnalisme et Santé, Université de
Bretagne Occidentale, Université Européenne de Bretagne, Brest; ${ }^{3}$ Hôpital d'Instruction des
Armées, Clermont-Tonnerre, Brest; ${ }^{4}$ Faculté de Médecine de Rennes, Département de Santé
Publique, Rennes

10.1136/oemed-2018-ICOHabstracts. 1096

Introduction Several studies have shown the high prevalence of burnout syndrome among hospital doctors. But this is not the only reaction disorder at work. There are also anxiety disorders, and post-traumatic stress disorder and mood disorders. This article reviews the knowledge of these disorders among hospital doctors.

Material and method this is a review of the literature between 01/01/2005 and 01/12/2016. The Medline and Scopus databases were used. The searches were done with keywords in English and French.

Results The prevalence of anxiety disorders among physicians ranged between $2.2 \%$ and $14.6 \%$. The prevalence of post traumatic stress ranged between $10.5 \%$ and $19.3 \%$. Several risk factors were significant, such as having had body fluid exposure, or the interaction between family and work life. The prevalence of mood disorders ranged between $7.8 \%$ and 